[CONTRIBUTION FROM THE ChEMICAL LABORATORY OF BROWN UNIVERSITY]

\title{
A STUDY OF SIDE-CHAIN OXIDATIONS WITH POTASSIUM PERMANGANATE. II
}

\author{
By Lucius A. BigeiLOW
}

Received December 15,1921

\section{Introduction}

An earlier communication ${ }^{1}$ reported the results of an investigation upon the oxidation of the 3 nitrotoluenes with potassium permanganate in alkaline solution.

The purpose of the present paper is to extend this work to a study of the oxidation of the isomeric bromotoluenes under somewhat similar conditions, and to compare the results in the two series fairly closely, in order to make any possible generalizations between them.

Discussion of the Oxidation of Ortho,- Meta- and Para-bromotoluene

None of the bromotoluenes was commercially available in quantity and, therefore, it was necessary to prepare all of them in the laboratory. The only suitable method for the preparation of the ortho compound seemed to be that starting from $o$-toluidine, and making use of the well-known Gattermann reaction. Hydrolysis of the $o$-toluidine diazonium salt was minimized by using constant-boiling hydrobromic acid, $(48 \% \mathrm{HBr})$ as the solvent, and by introducing the sodium nitrite in powdered form into the reaction mixture. In this manner quite sufficient yields were obtained.

The meta derivative was prepared from $p$-toluidine by acetylation, bromination, and subsequent saponification, yielding $m$-bromo- $p$-toluidine. The amino group in the latter compound was then removed by diazotization and reduction in alcoholic solution. The evolution of nitrogen was catalyzed by the addition of a small amount of copper powder which made the reaction proceed more smoothly.

It was found most convenient to prepare the para isomer from p-toluidine by means of the Sandmeyer reaction. This was slightly modified, however, by allowing the solution of the diazotized $p$-toluidine to flow gradually into the boiling cuprous bromide solution while a current of steam was passing through the latter. This had the effect of removing the product from the reaction mixture at the instant at which it was formed, which proved very advantageous.

Practical laboratory methods for carrying out these preparations will be found in the Experimental Part. The writer believes that yields have been obtained, in two cases at least, materially in excess of those to be found reported in the literature, and that the methods which have been

${ }^{1}$ Bigelow, This Journal, 41, 1559 (1919). 
developed tend to minimize the expenditure of time, effort and chemicals.

The oxidation of the bromotoluenes has been carried out entirely in alkaline or neutral media, and upon a moderately large laboratory scale. A product of high commercial quality and maximum yield has been the aim, rather than one of great purity, with decreased yield. Nearly all influences which have been brought to bear upon the oxidations have been found to have a considerable effect upon the reactions; but the result, in every case, has been merely to alter the proportion of bromotoluene attacked by the permanganate. When the yield of bromobenzoic acid was decreased the bromotoluene recovered unchanged was increased in the inverse ratio, so that the sum of the two remained essentially constant. Fxactly the same was true in the oxidation of the nitrotoluenes. This emphasizes the conclusions drawn in the earlier paper, namely: (1) the quantity of organic matter entirely destroyed during the reaction is practically independent of variations of procedure; (2) two entirely independent changes occur within the reacting mixture, (a) the oxidation of the side-chain to carboxyl, and (b) the decomposition of the permanganate into oxides of manganese and free oxygen; differing conditions merely accelerating the one or the other of these changes, causing various amounts of material to be attacked before all of the permanganate has been destroyed.

An increasing concentration of alkali in the oxidation mixture, beyond a certain very low concentration, hinders the oxidation of all three of the bromotoluenes. In the case of the meta isomer, however, this effect is not observed until the alkaline strength of the solution becomes very considerable. It is evident, then, that the presence of alkali does not accelerate significantly the rate of oxidation of any of the bromotoluenes, while it probably stimulates the decomposition of the permanganate to a certain extent. This is quite different from the results obtained with the nitrotoluenes, when increasing alkalinity of the reaction mixtures favored the oxidation of the ortho and para isomers, while it hindered that of the meta derivative. In the earlier work, it occurred to the writer that the increased susceptibility of $o$ - and $p$-nitrotoluenes to oxidation in the presence of alkali might be due to the fact that these derivatives can assume a quinoid structure, while the meta compound cannot. Aromatic compounds possessing a quinoid configuration are notably more sensitive to reagents than those which do not have this structure. Upon the basis of this explanation, the presence of alkali in the reacting mixture should have no effect upon the oxidation of the bromotoluenes, inasmuch as no quinoid configuration can be assigned to any of them.

When the quantity of potassium permanganate used in a bromotoluene oxidation is increased above the theoretical amount required, the result 
is rather peculiar. In general the reaction is favored, except perhaps when the oxidizing agent is present in great excess. In the case of the ortho, and meta derivatives, however, the effect was not entirely uniform, the oxidation being favored, retarded, and favored again, as the excess of permanganate was increased. Since this particular lack of uniformity was seen in the oxidation of two different bromotoluenes, and since the sum of the yield obtained and the unchanged material recovered remained essentially constant, it hardly seems possible to ascribe these variations to experimental inaccuracies. This result is very different from the corresponding one observed in the case of $p$-nitrotoluene, in which case an excess of permanganate greater than $10 \%$ above the calculated quantity merely destroyed more of the unchanged nitrotoluene, while the yield of acid remained constant. It does not appear possible to offer an explanation of these peculiarities in the present state of our knowledge of the mechanism of permanganate reactions.

An increasing dilution of the reaction mixture favors the oxidation of all the bromotoluenes, as it did the oxidation of all the nitrotoluenes. This is due without doubt to the fact that alkaline permanganate solutions have a decreasing tendency to dissociate into free oxygen and manganate, as they become more dilute.

The rate of reaction is approximately the same in the oxidation of the 3 bromotoluenes, although it is slightly greater in the case of the para compound than it is with the other two isomers. It is roughly $1 / 2$ as great as the rate of oxidation of the corresponding $o$ - and $m$-nitro compounds, and approximately $1 / 3$ that of the $p$-nitro derivative, in neutral solutions. Furthermore, it is not much affected by changes in the alkalinity of the reacting mixture. A decrease in concentration of the solution, nevertheless, cuts down the rate of reaction and the converse is true. The experimental results show that the $p$-bromotoluene gives the highest yield of the corresponding acid; the meta isomer next, and the ortho derivative lowest.

\section{Experimental Part}

Preparation of the Bromotoluenes. -The exact procedures found most advantageous for the synthesis of the 3 bromotoluenes are briefly summarized in the following paragraphs.

o-Bromotoluene.-One hundred and sixty-two g. of commercial o-toluidine is dissolved in $675 \mathrm{cc}$. of hydrobromic acid, sp. gr. 1.49 , b. p. $123-124^{\circ}$. The mixture is cooled to $10^{\circ}$ and $116 \mathrm{~g}$. of coarsely powdered sodium nitrite added to it, in $10 \mathrm{~g}$. portions. After each addition the flask is corked and vigorously shaken until the red fumes at first evolved are absorbed. The temperature must not be allowed to rise above $+10^{\circ}$ during the operation. Five g. of copper powder is next added, and the mixture cautiously heated on a water-bath under a reflux condenser. As soon as the first sign of reaction is observed, the flask is placed in ice water. Nitrogen is evolved very vigorously. When the action has subsided, the mixture is heated for $1 / 2$ hour on the boiling water-bath. 
Then 1 liter of water is added, and the product subjected to distillation with steam. The distillate is made alkaline, and extracted with ether which is subsequently removed by distillation. Finally the crude $o$-bromotoluene is heated to its boiling point to remove the last traces of ether and is obtained as a red oil weighing $142 \mathrm{~g}$. which is $59 \%$ of the calculated amount. These figures represent the average of two runs. The crude material may be purified by repeated fractional distillation through a column, and under favorable conditions the pure substance recovered is $73 \%$ of the crude material used. The final product, which is a colorless, highly refractive liquid, boiling at $181-182^{\circ}$ (corr.), is thus obtainable in $40 \%$ yield.

$m$-Bromotoluene.-One hundred and fifty g. of commercial $p$-toluidine is dissolved in $390 \mathrm{cc}$. of glacial acetic acid and the solution refluxed for $2^{1 / 2}$ hours. To this mixture, after cooling, is added gradually with vigorous stirring a solution of $75 \mathrm{cc}$. of bromine in $150 \mathrm{cc}$. of glacial acetic acid. The rate of addition should be such that the temperature rises to, but not above $50^{\circ}$. After standing for 10 minutes the clear red solution is poured into 6 liters of water, with vigorous stirring. The precipitated $m$-bromo-pacetotoluide is filtered, and dried until it weighs about $500 \mathrm{~g}$. It is now dissolved in $300 \mathrm{cc}$. of $95 \%$ alcohol and treated with $75 \mathrm{~g}$. of solid sodium hydroxide in 2 portions. A vigorous reaction occurs, and when this has subsided the mixture is poured into 1200 cc. of water. The oily $m$-bromo-p-toluidine which is precipitated is then drawn into a mixture of $600 \mathrm{cc}$. of $95 \%$ alcohol and $150 \mathrm{cc}$. of sulfuric acid, sp. gr. 1.84 . It is best to extract the aqueous layer with ether to recover the suspended oil. The alcohol solution is vigorously stirred and then diazotized, below $+10^{\circ}$, with $192 \mathrm{cc}$. of a solution of sodium nitrite containing $100 \mathrm{~g}$. in $175 \mathrm{cc}$. of solution. After the mixture has stood for a few minutes, $25 \mathrm{~g}$. of copper powder is added, and the solution warmed gently. Nitrogen is very rapidly evolved, and when the reaction has ceased the mixture is heated to boiling. Finally 2 liters of water is added, and the mixture distilled with steam. The crude product is separated from the aqueous portion of the distillate, and is a yellowish oil weighing about $138 \mathrm{~g}$. which is $59 \%$ of the calculated quantity calculated on the basis of the p-toluidine used. Very nearly $60 \%$ of this can be recovered as pure material and the final product, a colorless liquid boiling at $183-184^{\circ}$ (corr.), is obtained in $36 \%$ yield.

p-Bromotoluene.-Sixty-three $\mathrm{g}$. of cupric sulfate pentahydrate, $154 \mathrm{~g}$. of sodium bromide, $20 \mathrm{~g}$. of copper turnings, $30 \mathrm{~g}$. of sulfuric acid, sp. gr. 1.84 , and 1 liter of water are boiled together for several hours; $107 \mathrm{~g}$. of $p$-toluidine is dissolved in a mixture of $196 \mathrm{~g}$. of sulfuric acid, sp. gr. 1.84 , and 1 liter of water. The amine is diazotized, below $+20^{\circ}$, with $122 \mathrm{cc}$. of a solution of sodium nitrite containing $100 \mathrm{~g}$. in $175 \mathrm{cc}$. of solution. The clear cold solution of the diazonium salt is now allowed to flow very gradually into the boiling copper solution, and a vigorous current of steam is passed in at the same time. The distillate is made alkaline and extracted with ether. After the removal of the ether the residue of $p$-bromotoluene is heated to its boiling point to remove the last traces of ether; it is a yellow oil weighing $137 \mathrm{~g}$., which is $80 \%$ of the calculated amount. These figures represent an average of 3 runs. About $85 \%$ of this can be recovered as pure material. The final product, obtained in almost $70 \%$ yield, is a white crystalline solid, melting at $26^{\circ}$ and boiling at $184-185^{\circ}$ (corr.).

The $o-, m$-, and $p$-bromotoluenes submitted to oxidation were the purified products of the reactions described above. The potassium permanganate used as the oxidizing agent had been some years in the laboratory. It was analyzed to determine its oxidizing power, with the following results: $1 \mathrm{~g}$. $\mathrm{KMnO}_{4}=2.118 ; 2.116 \mathrm{~g} . \mathrm{Na}_{2} \mathrm{C}_{2} \mathrm{O}_{4}$; calc. $1 \mathrm{~g}$. $\mathrm{KMnO}_{4} \approx$ $2.123 \mathrm{~g}$. $\mathrm{Na}_{2} \mathrm{C}_{2} \mathrm{O}_{4}$. Therefore, the oxidizing power of the permanganate 
was $99.8,99.7 \%$ of the calculated amount, and it was employed directly as the oxidizing agent. The sodium hydroxide used was a high grade commercial product and the solvent employed was water. The oxidations were carried out in a copper kettle, made especially for this work. It was fitted with a reflux condenser and an efficient, motor-driven stirrer. The method of operation was essentially the same in every case, and will now be described briefly.

The water was first placed in the container and the sodium hydroxide weighed out and added to it. Twenty-five $g$. of bromotoluene was next weighed to $0.1 \mathrm{~g}$., and poured into the sodium hydroxide solution, which was subsequently heated nearly to boiling. The potassium permanganate was weighed and added to the hot mixture all at one time. The contents of the kettle were then heated to gentle boiling and vigorously stirred until the pink color due to the permanganate had disappeared. It was not suitable to add the permanganate in portions, as in the earlier work, as this procedure consumed too much time to be practical. When the oxidation was complete, the mixture was distilled with steam to recover the unchanged bromotoluene. The oil was separated from the distillate and weighed. The main solution was washed out of the kettle, allowed to cool, and filtered. The usually colorless filtrate, containing sodium bromobenzoate, was evaporated over a free flame to a convenient volume and again filtered to remove the last traces of oxides of manganese. The solution was finally concentrated to a definite volume and acidified while hot with conc. hydrochloric acid. After cooling the solution the bromobenzoic acid which had separated was filtered off, dried and weighed.

The time required for the oxidation of the bromotoluenes was from 6 to 8 hours, the color of the permanganate disappearing after that time. In recovering the unchanged material, where this was liquid, the steam distillate was received in a separating funnel. After standing overnight the clear lower layer was drawn off and weighed directly. The separation is good, and the results obtained in this way were quite satisfactory. This procedure is necessitated by the fact that the bromotoluenes are not only very appreciably volatile with the vapors of ether, but also retain ether quite tenaciously. Extraction, therefore, would yield no morc accurate results. In the case of the $p$-bromotoluene, which is a solid at ordinary temperatures, the steam distillate was cooled and filtered. The light yellow solid was dried overnight in a cool place, and weighed. It was dried for the same length of time in every case, inasmuch as the loss by direct evaporation of the solid is very appreciable. The sodium bromobenzoate solutions were in all cases colorless, or nearly so, and deposited the corresponding acids in a colorless crystalline condition upon acidification. Averages of several determinations showed that $500 \mathrm{cc}$. of the acid mother liquors retained approximately $0.6 \mathrm{~g}$. of $o$-bromobenzoic acid 
and $0.4 \mathrm{~g}$. of $m$-bromobenzoic acid. No determination was made for the para acid, as it is known to be very insoluble. ${ }^{2}$ While the alkaline bromobenzoate solutions were evaporated to about $500 \mathrm{cc}$. in the $o$ - and $m$ bromotoluene oxidations, and to about 1 liter in the oxidations of the para isomer, no correction has been made for the small amount of acid which was not precipitated. Representative samples of the acids gave only faint traces of residue upon ignition, and gave concordant melting points as follows: ortho, $146-147^{\circ}$; meta, $154-155^{\circ}$; para, $244-248^{\circ}$. The values given in the literature are: ortho, $147-148^{\circ}, 3150^{\circ} ;$ meta, $155^{\circ} ;{ }^{5}$ para, $250-251^{\circ} .^{2}$

The Influence of Alkali upon the Bromotoluene Oxidations.-The study of the influence of a varying concentration of alkali upon the yield obtained in, and the unchanged material recovered from the oxidation of the bromotoluenes, gave the following results.

TABLE I

$25 \mathrm{~g}$. of Bromotoluene, $51 \mathrm{~g}$. (10\% excess) of Potassium Permanganate, and $1500 \mathrm{cc}$. of Water were used in each Experiment. See Fig. 1

Ortho-bromotoluene

\begin{tabular}{|c|c|c|c|c|}
\hline Expt. & $\begin{array}{c}\text { Sodium } \\
\text { hydroxide } \\
\text { G. }\end{array}$ & $\begin{array}{c}\text { Unchanged } \\
\text { bromotoluene } \\
\text { G. }\end{array}$ & $\begin{array}{l}\text { Yield of } \\
\text { bromobenzoic } \\
\text { acid } \\
\text { G. }\end{array}$ & $\begin{array}{c}\text { Yield plus } \\
\text { unchanged } \\
\text { G. }\end{array}$ \\
\hline 1 & 0 & 7.7 & 12.9 & 21 \\
\hline $2^{a}$ & 2 & 8.5 & 14.2 & 23 \\
\hline 3 & 4 & 7.6 & 14.8 & 22 \\
\hline 4 & 8 & 8.4 & 14.1 & 23 \\
\hline 5 & 16 & 8.9 & 13.5 & 22 \\
\hline \multicolumn{5}{|c|}{ Meta-bromotoluene } \\
\hline $7^{a}$ & 0 & 6.9 & 17.5 & 24 \\
\hline $8^{a}$ & 2 & 6.2 & 17.7 & 24 \\
\hline 9 & 4 & 6.4 & 17.4 & 24 \\
\hline 10 & 8 & 6.9 & 17.7 & 25 \\
\hline 11 & 16 & 7.4 & 17.5 & 25 \\
\hline \multicolumn{4}{|c|}{ Para-bromotoluene } & 24 \\
\hline 13 & 0 & $\begin{array}{c}\text { Fara-dinato } \\
2.2\end{array}$ & 21.1 & 23 \\
\hline 14 & 2 & 2.2 & 22.2 & 24 \\
\hline 15 & 4 & 2.5 & 21.3 & 24 \\
\hline 16 & 8 & 3.3 & 21.2 & 25 \\
\hline 17 & 16 & 5.0 & 20.0 & 25 \\
\hline 18 & 32 & 6.2 & 19.0 & 25 \\
\hline 19 & 64 & 6.2 & 16.6 & 23 \\
\hline
\end{tabular}

a Average of two runs.

${ }^{2}$ Fittig and König, Ann., 144, 283 (1867).

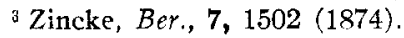

${ }^{4}$ Rahlis, Ann., 198, 99 (1879).

5 Friedburg, ibid., 158, 19 (1871). 
It thus appears that a certain small concentration of alkali is favorable to the oxidation, while an increase beyond this hinders the reaction very decidedly, at least in the cases of the ortho and para isomers. In the oxidation of the meta derivative, the concentration of alkali, unless high, has but little effect upon the yield of acid produced, although a gradual increase tends to cause more $m$-bromotoluene to remain unattacked. The

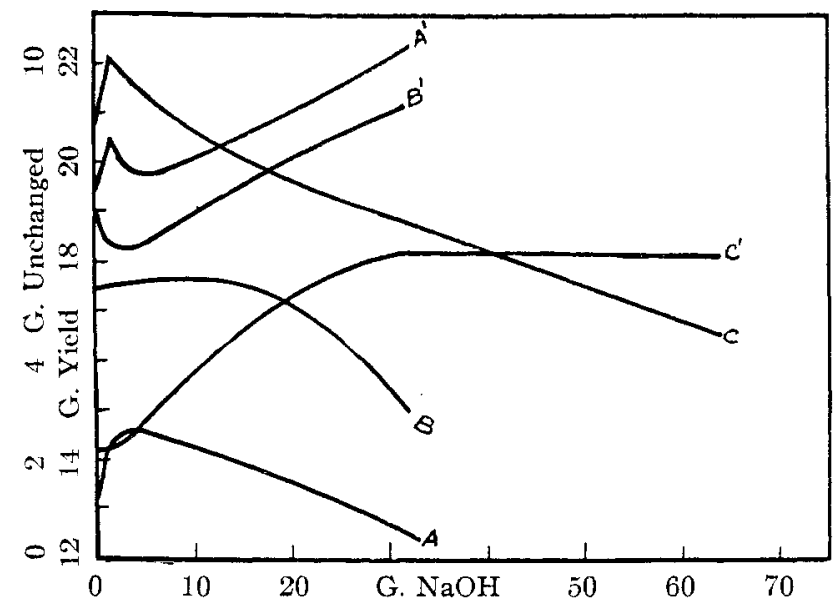

Fig. 1.-Bromobenzoic acids produced and bromotoluenes recovered $v s$, alkali. $\mathrm{A}$ is the yield of $o ; \mathrm{B}, m-;$ and $\mathrm{C}, p$-bromobenzoic acid; $\mathrm{A}^{\prime}$ is the unchanged $o-; \mathrm{B}^{\prime}, m-;$ and $\mathrm{C}^{\prime}, p$-bromotoluene.

small amount of unchanged material recovered in Expt. 1 is doubtless due, in part at least, to the peculiar fact that it is very difficult to distil the last traces of 0 -bromotoluene with steam from a neutral reaction mixture containing the oxides of manganese in suspension. This phenomenon was not observed in the oxidation of either of the other bromotoluenes.

The Influence of an Excess of Permanganate upon the Bromotoluene Oxidations.-The figures tabulated below express the results of experiments carried out to determine the effect of a gradually increasing excess of the oxidizing agent upon the reaction.

TABLE II

$25 \mathrm{~g}$. of Bromotoluene and $1500 \mathrm{cc}$. of Water used in each Experiment. See Fir. 2 Ortho-bromotoluene, with $4 \mathrm{~g}$. of sodium hydroxide

$\begin{array}{cccccc}\text { Expt. } & \begin{array}{c}\text { Perman- } \\ \text { ganate }\end{array} & \begin{array}{c}\text { Excess } \\ \text { G. }\end{array} & \begin{array}{c}\text { Unchanged } \\ \text { bromo- } \\ \text { toluene }\end{array} & \begin{array}{c}\text { Yield of } \\ \text { bromobenzoic } \\ \text { acid } \\ \text { G. }\end{array} & \begin{array}{c}\text { Yield } \\ \text { plus }\end{array} \\ \begin{array}{c}\text { unchanged } \\ 1\end{array} & 46.2 & 0 & 11.9 & 11.3 & \text { G. } \\ 2 & 51 & 10 & 7.6 & 14.8 & 22 \\ 3 & 55 & 20 & 7.0 & 14.4 & 21 \\ 4 & 60 & 30 & 6.2 & 15.1 & 21 \\ 5 & 65 & 40 & 5.9 & 17.2 & 23 \\ 6 & 69 & 50 & 4.7 & 17.0 & 22\end{array}$


Meta-bromotoluene, with no sodium hydroxide

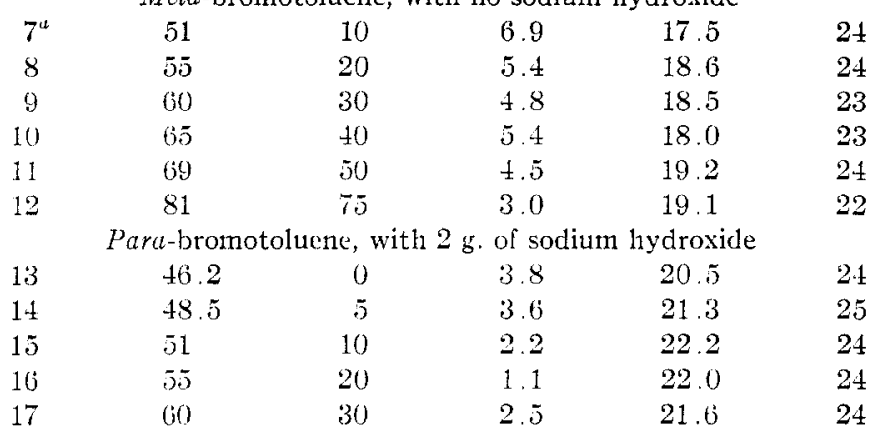

"Average of 2 runs.

It will be observed that the yield does not rise uniformly with the excess of permanganate. The somewhat favorable result in Expt. 2, however, corresponds to a $10 \%$ excess of the oxidizing agent, which was the proportion found most favorable in the nitrotoluene oxidations. In the case of the meta compound it is doubtful whether the increase in yield between

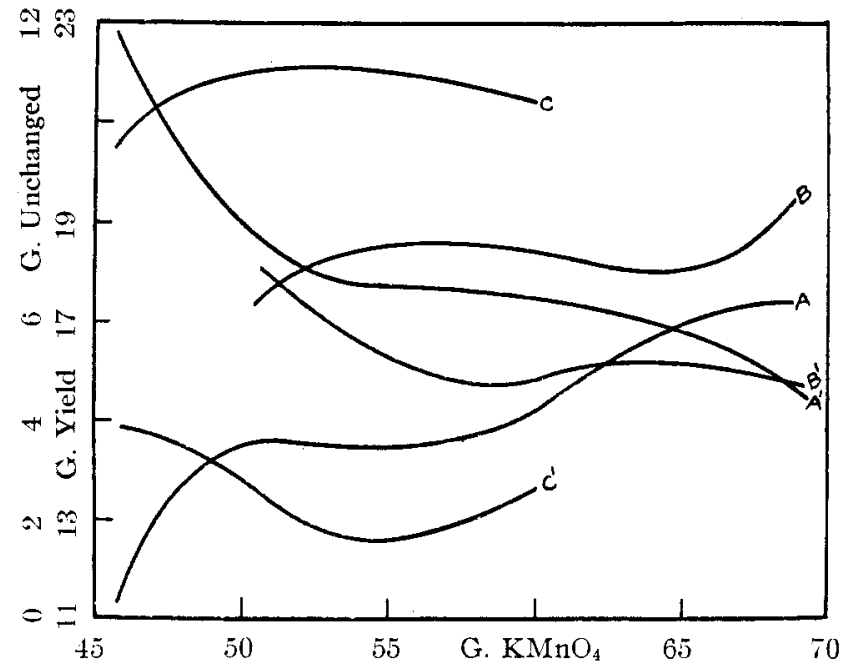

Fig. 2.-Bromobenzoic acids produced and bromotoluenes recovered $v s$. excess permanganate. $\mathrm{A}$ is the yield of $0-; \mathrm{B}, m-;$ and $\mathrm{C}, p$-bromobenzoic acid: $\mathrm{A}^{\prime}$ is the unchanged $o-; \mathrm{B}^{\prime}, m-;$ and $\mathrm{C}^{\prime}$, p-bromotoluene.

Expts. 8 and $11(0.6 \mathrm{~g}$.$) is really worth the permanganate consumed to ob-$ tain it. Whether or not there would be a further increase in the yield of $p$-bromo-benzoic acid if an excess of permanganate above $30 \%$ were used, has not been determined, but even if there were, it is very doubtful whether it would be great enough to warrant the use of so great an excess of the oxidizing agent. The peculiar shape of the curves (Fig. 2), and especially their general similarity, is worthy of note. 
The Influence of Dilution upon the Bromotoluene Oxidations.-The results of the experiments carried out to determine the influence of the dilution of the solution in which the reactions were carried out are collected in the following table.

\begin{tabular}{|c|c|c|c|c|c|}
\hline & & & & & \\
\hline & $25 \mathrm{~g}$. of & motoluene & sed in each & xperiment & \\
\hline & Ortho-bron & oluene, wi & $4 \mathrm{~g}$ of sod & n hydroxi & \\
\hline Iixpt. & $\begin{array}{c}\text { Water } \\
\text { ce. }\end{array}$ & $\begin{array}{c}\text { l'ermiall- } \\
\text { gatlate } \\
\text { (i. }\end{array}$ & $\begin{array}{l}\text { Unchanged } \\
\text { bromo- } \\
\text { toluene } \\
G .\end{array}$ & $\begin{array}{l}\text { Yield of } \\
\text { bromo- } \\
\text { benzoic } \\
\text { acid } \\
\text { a. }\end{array}$ & $\begin{array}{c}\text { Yield } \\
\text { plus } \\
\text { unchanged } \\
G .\end{array}$ \\
\hline 1 & 750 & 51 & 11.4 & 11.1 & 23 \\
\hline 2 & 1500 & 51 & 7.6 & 14.8 & 22 \\
\hline 3 & 3000 & 51 & 8.2 & 14.5 & 23 \\
\hline & Meta-brom & bluene, wit & $2 \mathrm{~g}$. of sodi & hydroxic & \\
\hline 4 & 750 & 55 & $3.3^{a}$ & 14.9 & 18 \\
\hline 5 & 1500 & 55 & 6.0 & 17.7 & 24 \\
\hline 6 & 3000 & 55 & 4.5 & 21.5 & 26 \\
\hline & Para-brom & biuene, wit & $2 \mathrm{~g}$. of sodi & hydroxic & \\
\hline 7 & 750 & 51 & 4.6 & 19.1 & 24 \\
\hline 8 & 1500 & 51 & 2.2 & 22.2 & 24 \\
\hline 9 & 3000 & 51 & 2.2 & 22.7 & 25 \\
\hline
\end{tabular}

"This very low figure is doubtless due to an undetected loss.

In all cases an increasing dilution greatly favored the reactions, the cffect being especially marked in the oxidation of $m$-bromotoluene. While a dilution corresponding to 3 liters of water for a $25 \mathrm{~g}$. sample gave the best restults in 2 series out of the 3 , it seems that the increased yield hardly compensates the difficulty of handling the larger volume of solution.

An experiment carried out to determine the effect of adding the potassium permanganate in 2 equal portions resulted in a decreased yield, while the reaction time was almost doubled, as compared with the results obtained under the same conditions when the oxidizing agent was added all at one time. A similar comparison showed that the use of the mechanical stirrer increased the yield by exactly $50 \%$ and cut the reaction time very nearly in half.

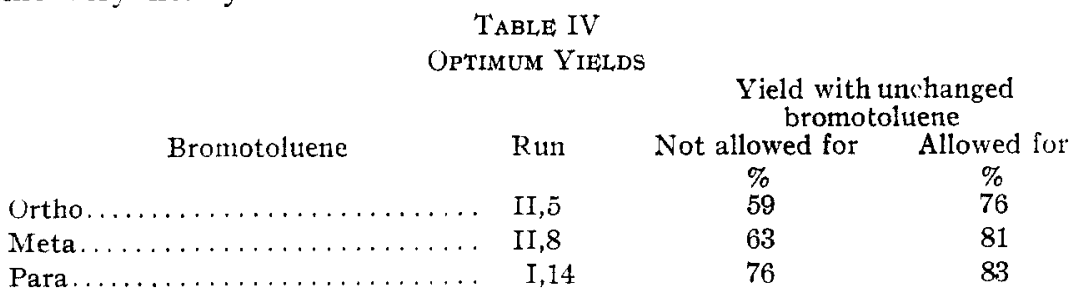

\section{Summary}

A comparative study has been made of certain influences which affect the oxidation of the three bromotoluenes by potassium permanganate in alkaline solution. The essential results obtained were as follows. 
1. A gradually increasing concentration of alkali in the reaction mixtures is on the whole unfavorable to the oxidation of all the bromotoluenes. A slightly alkaline solution is, however, more favorable than an entirely neutral medium.

2. An increasing dilution of the solution is favorable to the oxidation of all the bromotoluenes.

3. An excess of oxidizing agent above the calculated amount is favorable in all cases.

4. While the rates of oxidation of the bromotoluenes are essentially the same, the para compound gives the highest yield of the corresponding acid, the meta isomer next, and the ortho derivative the lowest.

5 . The essential point of difference between the results as above expressed, and those obtained in a similar investigation of the oxidation of the nitrotoluenes, is the fact that the presence of alkali in the reacting mixture was very favorable to the oxidation of $o$ - and $p$-nitrotoluene, while it is not so in the case of the corresponding bromotoluenes.

PROVIDENCE, RHODE ISLAND

[Con'tribution from the Division of Agricultural Chemistry of purdue: UNIVERSITY]

\title{
CHARACTERISTIC PROTEINS IN HIGH- AND LOW-PROTEIN CORN
}

\author{
By M. F. Showalter AND R. H. Carr \\ Received April 15, 1922
}

the nitrogen content of corn is subject to wide variations by breeding and selection.

Osborne and Mendel $^{1}$ reported a sample containing $2.33 \%$ of nitrogen, while in a more recent paper by Spitzer, Carr and Epple ${ }^{2}$ samples containing as low as $1.35 \%$ were reported. Average corn contains about $1.70 \%$ of nitrogen. The ear of highest nitrogen content that the writers have been able to produce is 2.95 and the lowest $1.29 \%$ of nitrogen. Since proteins are so important in nutrition it seems desirable to know whether the distribution of the various protcins is the same in high-nitrogen corn as in that of low nitrogen content, and if not to know wherein the difference lies.

Soave, ${ }^{3}$ an Italian worker, stated that the zein contains $32.65 \%$ of the total nitrogen of the corn kernel. Osborne and Mendel reported $22 \%$ of the total protein of corn with which they worked to be soluble in $10 \%$ potassium chloride solution, $41 \%$ soluble in $90 \%$ alcohol, $31 \%$ soluble in $0.2 \%$ potassium hydroxide solution, and $6 \%$ as insoluble and loss. Spitzer, Carr and Epple ${ }^{2}$ found $5.27 \%$ of the total nitrogen present as amides, $21.61 \%$ as globulin etc. (soluble in $10 \%$ sodium chloride solution), $29.41 \%$ as zein (soluble in $90 \%$ alcohol), and $42.85 \%$ as glutelin. From these data it is evident that there is a lack of agreement as to the distribution of the various proteins in corn. It is to be noted, however, that corn of relatively high nitrogen content $(2.33 \%)$ was used

\footnotetext{
${ }^{1}$ Osborne and Mendel, J. Biol. Chem., 18, 1 (1914).

2 Spitzer, Carr and Epple, This Journal, 41, 1212 (1919).

${ }^{3}$ Soave, C. A., 2, 150 (1908); Staz. Sper. Agr. Ital., 40, No. 3, 193-207 (1907).
} 